\title{
Impact of conditional deletion of the pro-apoptotic BCL-2 family member BIM in mice
}

\author{
MJ Herold ${ }^{1,2}$, R Stuchbery ${ }^{1,2}$, D Mérino ${ }^{1,2}$, T Willson $^{1,2}$, A Strasser $^{1,2}$, D Hildeman ${ }^{3}$ and P Bouillet ${ }^{\star, 1,2}$
}

The pro-apoptotic BH3-only BCL-2 family member BIM is a critical determinant of hematopoietic cell development and homeostasis. It has been argued that the striking hematopoietic abnormalities of BIM-deficient mice (accumulation of lymphocytes and granulocytes) may be the result of the loss of the protein throughout the whole animal rather than a consequence intrinsic to the loss of BIM in hematopoietic cells. To address this issue and allow the deletion of BIM in specific cell types in future studies, we have developed a mouse strain with a conditional Bim allele as well as a new Cre transgenic strain, Vav-CreER, in which the tamoxifen-inducible CreER recombinase (fusion protein) is predominantly expressed in the hematopoietic system. We show that acute loss of BIM in the adult mouse rapidly results in the hematopoietic phenotypes previously observed in mice lacking BIM in all tissues. This includes changes in thymocyte subpopulations, increased white blood cell counts and resistance of lymphocytes to BIM-dependent apoptotic stimuli, such as cytokine deprivation. We have validated this novel conditional Bim knockout mouse model using established and newly developed CreER strains (Rosa26-CreER and Vav-CreER) and will make these exciting new tools for studies on cell death and cancer available.

Cell Death and Disease (2014) 5, e1446; doi:10.1038/cddis.2014.409; published online 9 October 2014

The mitochondrial (also called intrinsic, stress or BCL-2 regulated) apoptotic pathway is regulated by members of the BCL-2 family. ${ }^{1}$ This protein family can be divided into prosurvival (A1, MCL-1, BCL-2, BCL-XL and BCL-W) and proapoptotic members. The latter can be further sub-divided into the BH3-only (BIM, PUMA, BID, BAD, NOXA, HRK, BMF, BIK) and the multi-BH domain members (BAX, BAK and possibly $\mathrm{BOK})^{2}$ Pro-survival BCL-2 family members protect cells from dying through binding and neutralizing the pro-apoptotic BCL-2 family members. Upon an apoptotic stimulus, the levels of certain $\mathrm{BH} 3$-only proteins increase as a result of transcriptional and/or post-transcriptional upregulation. These BH3only proteins activate the multi-domain members BAX and BAK either directly, or indirectly through neutralizing the prosurvival BCL-2 family members. ${ }^{3,4}$ Activated BAX and BAK oligomerize and form pores into the outer mitochondrial membrane, leading to the release of apoptogenic factors, such as cytochrome $c$, provoking the activation of the so-called caspase cascade with subsequent demolition of the cell. ${ }^{3}$

BIM is a critical initiator of the mitochondrial apoptotic pathway, particularly in hematopoietic cells. ${ }^{5}$ During B- and T-cell development, BIM activity is required to eliminate autoreactive lymphocytes. ${ }^{6,7}$ Constitutive loss of BIM (in all cell types) leads to the accumulation of lymphocytes that infiltrate non-hematopoietic organs, such as lungs, kidneys, liver and salivary glands, produce autoantibodies and on a mixed C57BL/6x129SV background this causes severe autoimmune disease resembling systemic lupus erythematosus. ${ }^{5} \mathrm{BIM}$ is also an important factor in peripheral
T-cell apoptosis during the shutdown of an immune response. $^{8,9}$ BIM is a tumor suppressor in mantle cell lymphoma, where the gene is lost, ${ }^{10}$ as well as Burkitt's lymphoma and renal carcinoma in which the gene is silenced. ${ }^{11,12}$ Loss of BIM renders cells resistant to several pro-apoptotic stimuli, such as withdrawal of growth factors, treatment with calcium ionophores ${ }^{5}$ or ER stress. ${ }^{13}$

This information about BIM's physiological function was derived from the study of a mouse strain in which the Bim gene was constitutively inactivated in all cell types. ${ }^{5}$ The complete absence of a gene product during the entire life of an animal can lead to phenotypes that are not cell-autonomous and may also lead to compensatory events (for example, upregulation of genes with overlapping function). Therefore techniques have been developed so that a gene of interest can be conditionally inactivated in a tissue-specific and/or temporally controllable manner using the Cre/Lox system. ${ }^{14} \mathrm{~A}$ further refinement of this technique consisted in engineering an inducible Cre recombinase by fusing it with a modified hormone-binding domain of the estrogen receptor (CreER) ${ }^{15}$ In the absence of 4 -hydroxytamoxifen (4-OHT), the CreER protein is sequestered in an inactive state in the cytosol. Upon administration of 4-OHT, the ER domain of the CreER fusion protein changes conformation, prompting the translocation of the fusion protein into the nucleus where the recombinase can delete DNA sequences flanked by loxP sites. ${ }^{15}$

We developed a conditional Bim allele allowing for temporally and spatially controllable deletion of this critical

\footnotetext{
${ }^{1}$ Molecular Genetics of Cancer Division, The Walter and Eliza Hall Institute of Medical Research, Parkville, Victoria, Australia; ${ }^{2}$ Department of Medical Biology, The University of Melbourne, Melbourne, Victoria, Australia and ${ }^{3}$ Division of Cellular and Molecular Immunology, Department of Pediatrics, Cincinnati Children's Hospital Medical Center, University of Cincinnati, Cincinnati, OH, USA

${ }^{*}$ Corresponding author: P Bouillet, The Walter and Eliza Hall Institute of Medical Research, 1G Royal Parade, Parkville, Victoria 3052, Australia, Tel: +61 393452334 ; Fax: +61 39347 0852; E-mail: bouillet@wehi.edu.au

Abbreviations: 4-OHT, 4-hydroxytamoxifen; WBC, white blood cells; PMA, phorbol ester; lono, ionomycin; Treg, regulatory T cells; Tg, transgenic

Received 27.5.14; revised 21.8.14; accepted 26.8.14; Edited by G Melino
} 
apoptosis initiator. In addition, we developed a novel strain, which expresses the CreER fusion protein under the control of the pan-hematopoietic Vav promoter. ${ }^{16}$ We show that the deletion of Bim in the adult mouse through activation of the CreER recombinase, using the Vav-CreER or the ubiquitously expressed Rosa-CreER transgene, caused hematopoietic abnormalities that were similar to those found in the constitutive Bim knockout animals. These novel strains (conditional Bim ko and Vav-CreER) will allow further detailed genetic investigations of cell death and tumourigenesis.

\section{Results}

BIM expression and phenotype in mice with floxed Bim alleles before and after Cre-mediated recombination. The BH3-only protein BIM is the most critical initiator of apoptosis in hematopoietic cell development and homeostasis. ${ }^{5}$ Mice constitutively deficient for BIM show many abnormalities, including increased white blood cell (WBC) counts, splenomegaly and defects in thymic T-cell selection. ${ }^{6}$ As these defects could potentially be affected by the absence of BIM (i) in non-hematopoietic cells or (ii) be dependent on absence of BIM during embryonic development, we decided to generate mice with a conditional Bim allele $\left(\operatorname{Bim}^{f f}\right)$, to allow specific deletion of Bim in a time- and/or tissue-specific manner. Coding exons 2, 3 and 4 of $\mathrm{Bim}^{17}$ were flanked by loxP sites. ${ }^{18}$ As expected, BIM protein expression and hematopoietic cell composition, WBC counts, spleen weights and thymic cell subset distribution, were comparable between $\mathrm{Bim}^{\mathrm{fl} / \mathrm{fl}}$ and wt mice (Figure 1). Crossing $\mathrm{Bim}^{f / f l}$ mice with the CMV-Cre deleter strain ${ }^{19}$ resulted in the

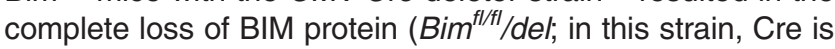
active in the early embryo) (Figure 1a) and the concomitant increase of WBC counts (Figure 1b) and spleen weights (Figure 1c), as well as the altered distribution of thymocyte populations (Figure 1d). These results demonstrate that (i) the loxP sequences do not alter the expression of the BIM protein or its function and (ii) that deletion of the floxed Bim allele recapitulates the phenotype observed in the constitutive Bim knockout mice.

Induced deletion of Bim in adult mice results in phenotypic alterations similar to those observed in constitutive Bim knockout mice. The advantage of a conditional Bim allele is the possibility to delete the gene in a temporally and cell type-controllable manner. In order to delete Bim at a predetermined time specifically in hematopoietic cells of adult mice, we generated a new transgenic mouse model, in which the tamoxifen-inducible CreERT2 recombinase $^{20}$ is expressed under the control of the panhematopoietic Vav promoter (Vav-CreER). ${ }^{16}$ To induce Bim deletion, 12-20-week-old Bim $^{f / f l} /$ Vav-CreER-tg mice were administered 4-OHT by oral gavage. Four weeks after the treatment, lymph nodes, spleens and thymi were collected

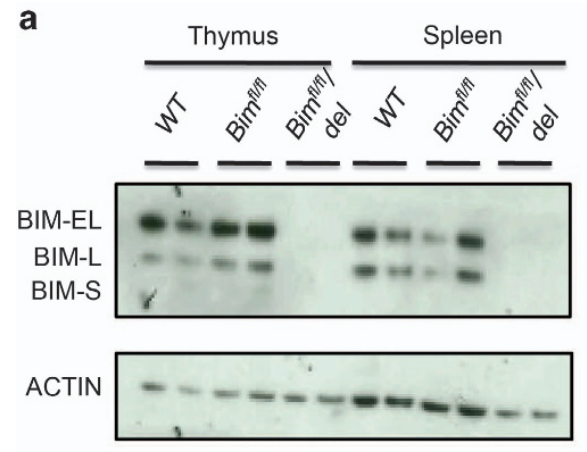

C

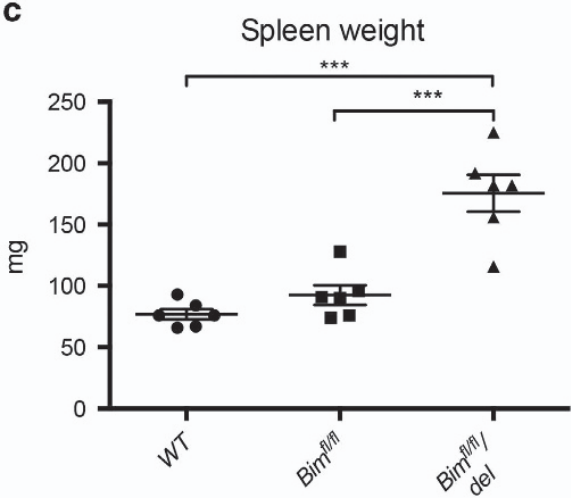

b

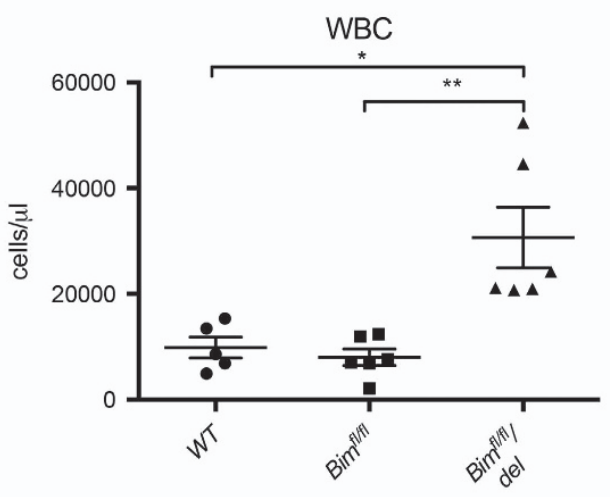

d

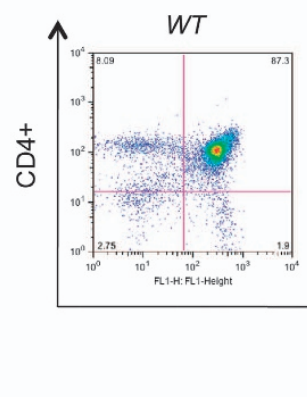

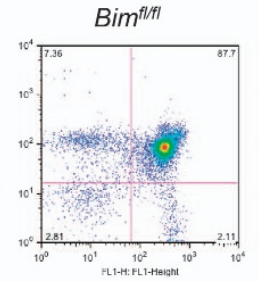

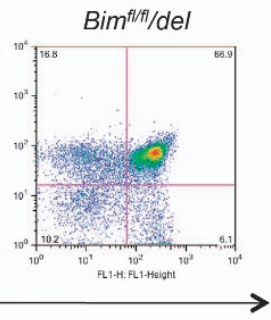

CD8+

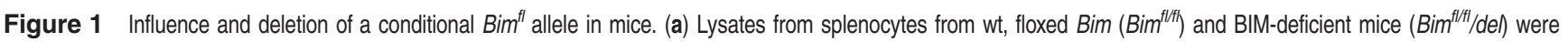
immunoblotted for BIM. Probing for $\beta$-actin served as a loading control. $N=2$ mice per genotype were tested, six independent experiments were performed. (b) White blood cell

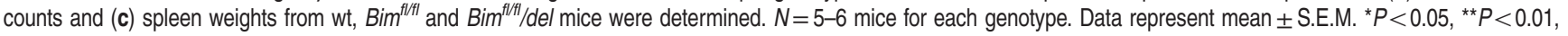
${ }^{* * *} P<0.001$ (paired $t$-test). (d) Thymocytes from mice of the indicated genotypes were isolated and single-cell suspensions stained with anti-CD4-PE (clone\# YTA3.2.1) and antiCD8-FITC (clone\# 53.6.7.2). Dead cells were excluded from analysis by staining with $10 \mu \mathrm{g} / \mathrm{ml}$ propidium iodide (PI; Sigma-Aldrich) 
from 4-OHT-treated Bim ${ }^{f l / f l}$, Vav-CreER, Bim ${ }^{f l / f l} /$ Vav-CreER as well as $\mathrm{Bim}^{-/-}$mice, and BIM protein levels were measured by intracellular FACS analysis (Figure 2a). As expected, the BIM protein levels in cells from 4-OHT-treated $\mathrm{Bim}^{f / f l} / \mathrm{Vav}$ CreER mice were comparable to those seen in cells from $\mathrm{Bim}^{-1-}$ mice, whereas the presence of the floxed $\operatorname{Bim}\left(\mathrm{Bim}^{\mathrm{fl} / \mathrm{fl}}\right)$ alleles or CreER (Vav-CreER) transgene had no impact on BIM protein expression when CreERT2 was not activated. This indicated that both $\mathrm{Bim}^{f l}$ alleles had been successfully recombined in Bim $^{f / f l} / \mathrm{Vav}$-CreER hematopoietic cells of tamoxifen-treated mice, explaining why the BIM protein was no longer present in these cells. To further validate the efficiency of the Vav-CreER strain, we crossed this strain to mice harboring a floxed allele of $\mathrm{Mcl}-1\left(\mathrm{Mcl}^{\mathrm{fl}}\right)$ and treated $\mathrm{Mcl}-1^{\mathrm{fl} / \mathrm{+}} / \mathrm{Vav}$-CreER-tg animals with three doses of $4-\mathrm{OHT}$. As the deletion of the floxed $\mathrm{Mcl}-1$ allele leads to the expression of the hCD4 reporter, ${ }^{21,22}$ we analyzed the blood of $\mathrm{Mcl}-1^{\mathrm{fl} / \mathrm{+}} \mathrm{Nav}-\mathrm{CreER}$-tg two days post treatment by flow cytometry for hCD4 expression (Supplementary Figure 1). This revealed that $\sim 20 \%$ of cells had recombined the floxed $\mathrm{Mcl}-1$ allele within 1 day, validating the utility of the Vav-CreER strain.
We also crossed the Bim $^{f / f l}$ mice with the Rosa-CreER transgenic strain, in which the ubiquitously expressed CreER protein causes the deletion of Bim in the entire organism upon 4-OHT treatment. ${ }^{23}$ Three to four weeks after 4-OHT treatment, BIM protein levels were examined by intracellular FACS analysis. Cells from the lymph nodes, thymus and spleen of

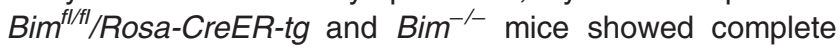
absence of the BIM protein, whereas cells from $\mathrm{Bim}^{f / f f}$ or $\mathrm{Bim}^{+/+} /$Rosa-CreER-tg mice expressed similar levels of BIM protein as the corresponding cells from wt mice (Figure $2 b$ ). As in the Rosa-CreER-tg mice, the CreER transgene is ubiquitously expressed, we also analyzed the deletion of the BIM protein in non-haematopoietic tissues (liver, kidney) of 4-OHT-

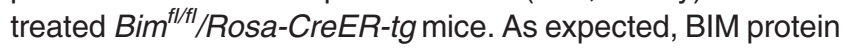
was almost undetectable in these organs, whereas treatment of Rosa-CreER-tg mice with 4-OHT had no impact on BIM protein levels (Supplementary Figure 2).

These results demonstrate that recombination of the floxed Bim locus can be successfully achieved in the adult mouse using two different 4-OHT-inducible Cre strains (Vav-CreER and Rosa-CreER). a
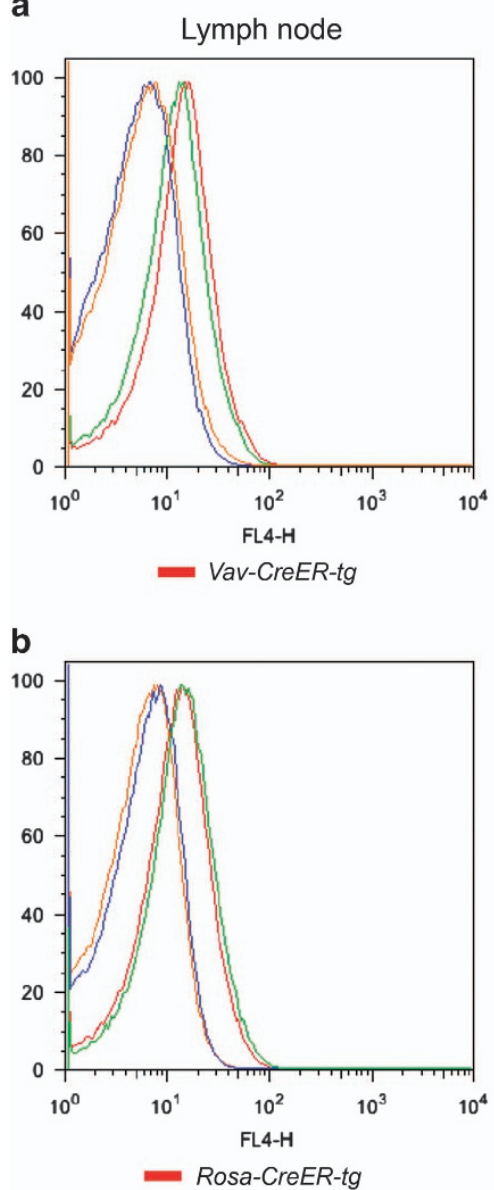

Spleen
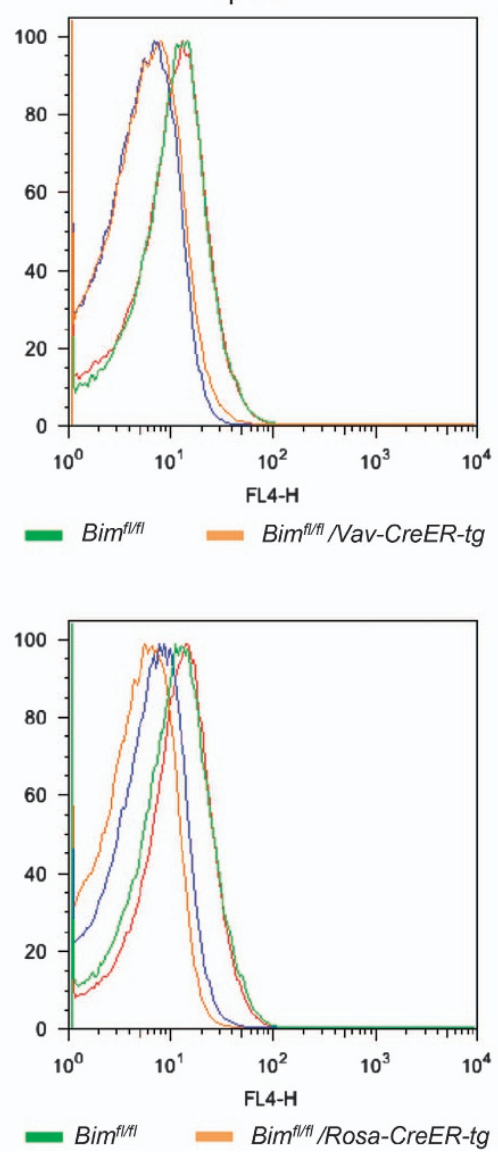

Thymus
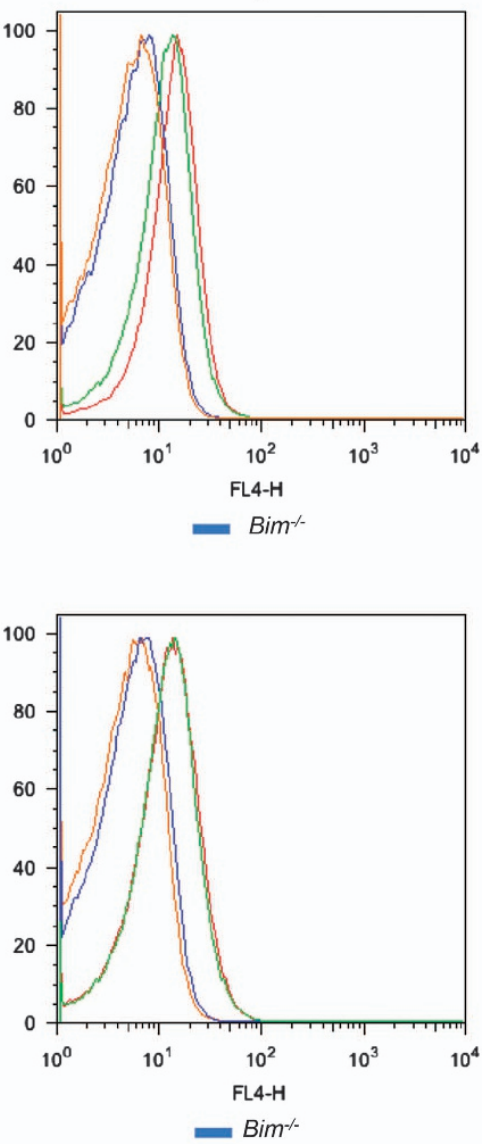

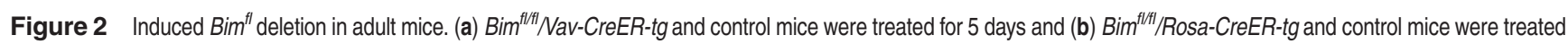
three times within 5 days ( 1 day break in between dosing) with a daily dose of $4.8 \mathrm{mg}$ Tamoxifen (4-OHT; Sigma) by oral gavage and then left untreated for 1 month or 3 weeks, respectively. Each FACS plot is representative of $N>3$ repeat experiments 
As loss of BIM in the entire mouse leads to increased WBC numbers, ${ }^{5}$ we analyzed the blood from Bim $^{f / / f l} / \mathrm{Nav}$-CreER-tg and $\mathrm{Bim}^{f / / f l} /$ Rosa-CreER-tg mice 3-4 weeks after 4-OHT treatment (Figure 3). As anticipated, induced loss of BIM caused an increase in WBC numbers in both $\mathrm{Bim}^{f / f l} / \mathrm{Vav}$ CreER-tg and Bim ${ }^{f l / f l} /$ Rosa-CreER-tg animals, albeit to different levels (Figure 3a). The larger increase observed in the $\mathrm{Bim}^{f l / f l} /$ Rosa-CreER-tg animals probably reflects a faster deletion of $\mathrm{Bim}^{f l}$ alleles in these animals. 4-OHT-treated Bim $^{f / f l} /$ Vav-CreER-tg and Bim ${ }^{f l / f l} /$ Rosa-CreER-tg mice also showed similarly abnormal distribution of thymocyte subpopulations, comparable to what is seen in $\mathrm{Bim}^{-/-}$mice. This is characterised by abnormally high frequencies of doublenegative $\left(\mathrm{CD}^{-} \mathrm{CD}^{-}\right)$and single-positive $\left(\mathrm{CD} 4^{+} \mathrm{CD} 8^{-}, \mathrm{CD}^{-}\right.$ $\mathrm{CD}^{+}$) thymocytes and reduced proportions of double-positive $\left(\mathrm{CD} 4^{+} \mathrm{CD}^{+}\right)$thymocytes compared with control (wt) mice a

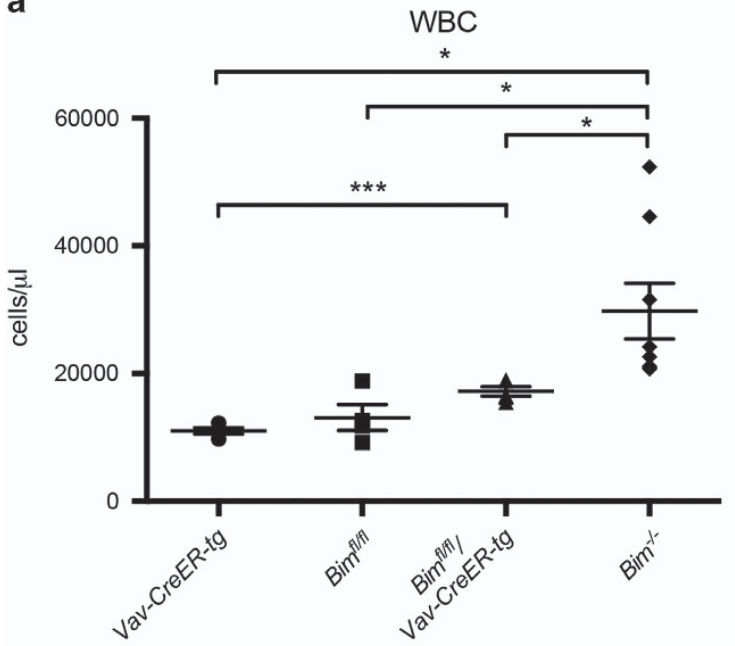

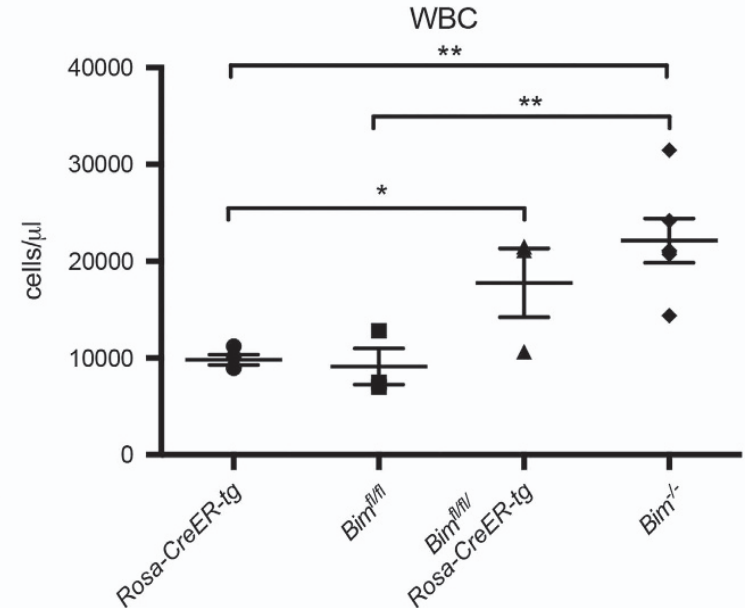

b
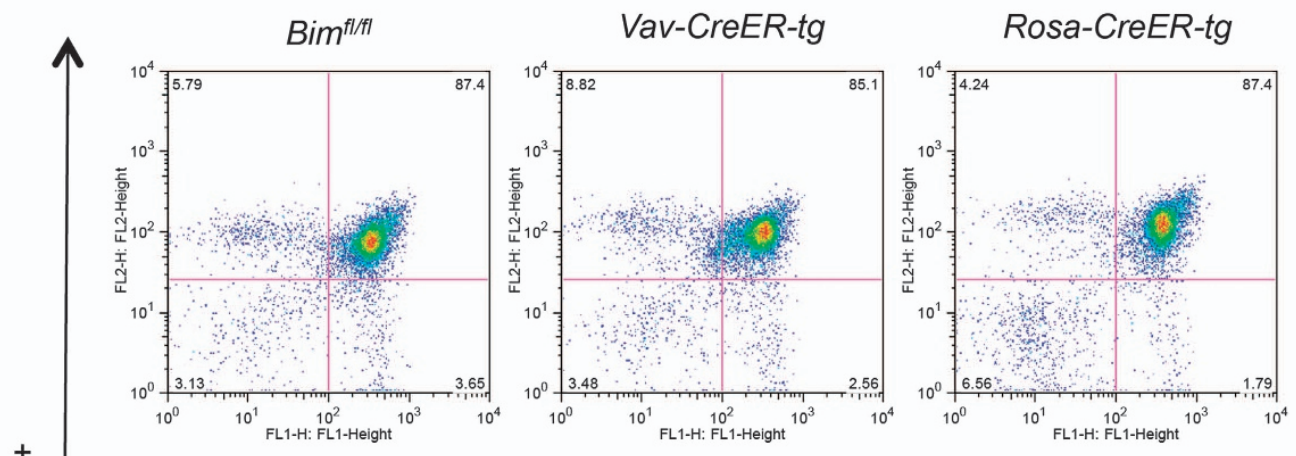

๖ั๋

$\operatorname{Bim}^{f l f l} /$

Vav-CreER-tg

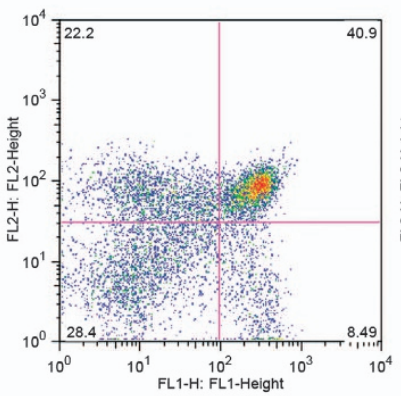

$\operatorname{Bim}^{f l / f l} /$

Rosa-CreER-tg

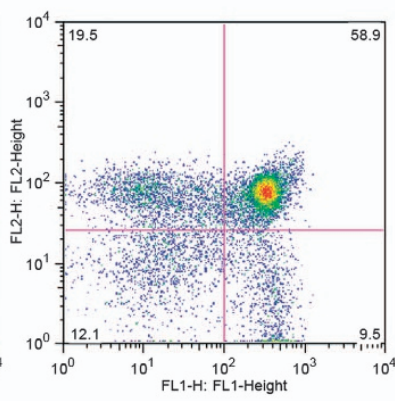

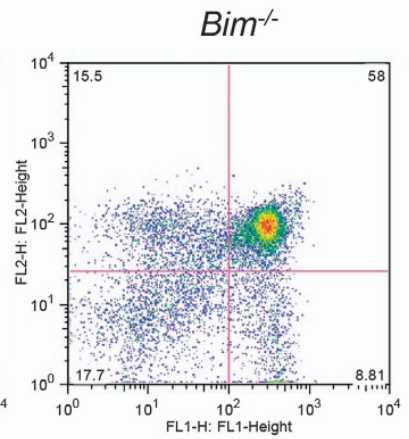

\section{CD8+}

Figure 3 Induced deletion of $\mathrm{Bim}^{f l}$ in mature animals leads to increased WBC numbers and abnormalities in the composition of thymocyte subpopulations. Blood from

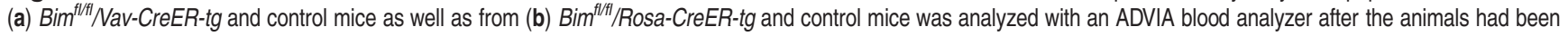
treated with 4-OHT, as described in Figure 2. (c) Thymocytes of mice of the indicated genotypes from $\mathbf{a}$ and $\mathbf{b}$ were stained with anti-CD4-PE and anti-CD8-FITC and analyzed by flow cytometry. $N=4-8$ mice for each genotype. Data represent mean \pm S.E.M. ${ }^{*} P<0.05,{ }^{\star \star} P<0.01,{ }^{* \star \star} P<0.001$ (paired $t$-test) 
(Figure 3b). This indicates that, although $\mathrm{Bim}^{f l}$ deletion might occur at a slower rate in peripheral lymphoid organs of $\mathrm{Bim}^{\mathrm{fl} / \mathrm{fl}} /$ Vav-CreER-tg mice compared with the Bim $^{f / / f l} /$ Rosa-CreER-tg animals, $B i m^{f l}$ recombination in thymocytes (or their precursors) appears to occur at similar rates in both strains.

Induced deletion of Bim in the adult mouse protects thymocytes from BIM-dependent apoptotic stimuli. BIMdeficient thymocytes are resistant to a variety of pro-apoptotic stimuli. ${ }^{5}$ We therefore compared the response of thymocytes from $\mathrm{Bim}^{-/}$, Bim ${ }^{f l / f l} / \mathrm{Nav}-C r e E R-t g, \quad \mathrm{Bim}^{f l / f t} /$ Rosa-CreER-tg, $\mathrm{Bim}^{f / f f l}$, Vav-CreER and Rosa-CreER mice, which had been treated with 4-OHT four weeks prior to organ isolation, to diverse cytotoxic stimuli. Thymocytes of the different genotypes were cultured in medium (medium; mimicking cytokine withdrawal) or treated with BIM-dependent (lonomycin $=$ lono) and BIM-independent (phorbol ester = PMA) apoptotic stimuli (Figure 4). Although thymocytes from mice of all genotypes were killed at a similar rate when treated with PMA (kills in a PUMA-dependent manner ${ }^{24}$ ), untreated (medium) and lonomycin-treated thymocytes from 4-OHT-treated $\mathrm{Bim}^{-/}$, Bim ${ }^{f / f l} / \mathrm{Vav}$-CreER-tg and Bim ${ }^{f / f l} /$ Rosa-CreER-tg mice all showed a marked survival advantage when compared with thymocytes from 4-OHT-treated Bim ${ }^{f / f l}$, Rosa-CreER-tg and Vav-CreER-tg mice. This demonstrates that constitutive or induced deletion of $\mathrm{Bim}$ in thymocytes leads to a similar resistance to these apoptotic stimuli, and that the observed change in thymocyte distribution is a consequence of the loss of BIM and not due to other abnormalities caused by Cremediated recombination.

\section{Discussion}

We report here the development of a new floxed Bim allele, which allows the deletion of this pro-apoptotic BH3-only protein in a cell type-restricted and temporally controllable manner. Using the well-established Rosa-CreER and newly developed Vav-CreER transgenic strains, deletion of Bim in the adult mice results in the same phenotype as that observed in the constitutive Bim knockout mice. It thus appears that the hematopoietic phenotype associated with the constitutive loss of BIM in all cell types reported previously ${ }^{5}$ is intrinsic to the hematopoietic system rather than a consequence of an unrecognized developmental defect due to the absence of BIM.

Our studies clearly show that the floxed Bim allele is functional and can be efficiently deleted by CreER recombinases. Importantly, these $\mathrm{Bim}^{f / f l}$ mice have recently been used in two other studies, ${ }^{18,25}$ in which Bim was specifically deleted in the regulatory T-cell lineage (Treg) only. This new mouse strain will thus be a valuable tool to further dissect the role of BIM in various cell types.

Importantly, our new Vav-CreER transgenic strain showed the same deletion efficiency of the floxed Bim alleles 4 weeks after 4-OHT treatment as the very well-characterised and widely used Rosa-CreER strain. ${ }^{23}$ However, when we tested a

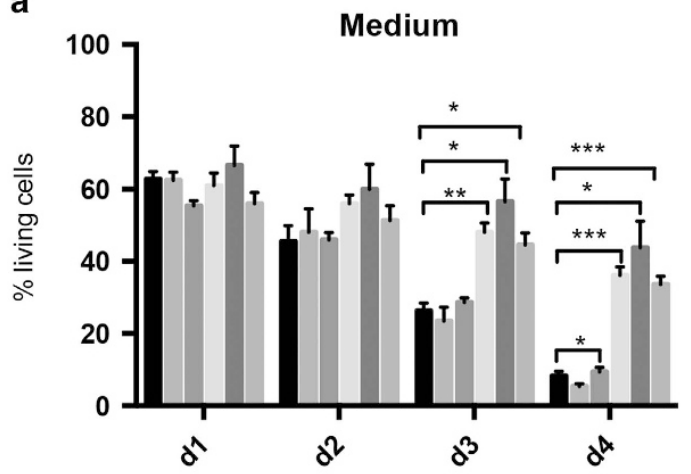

b

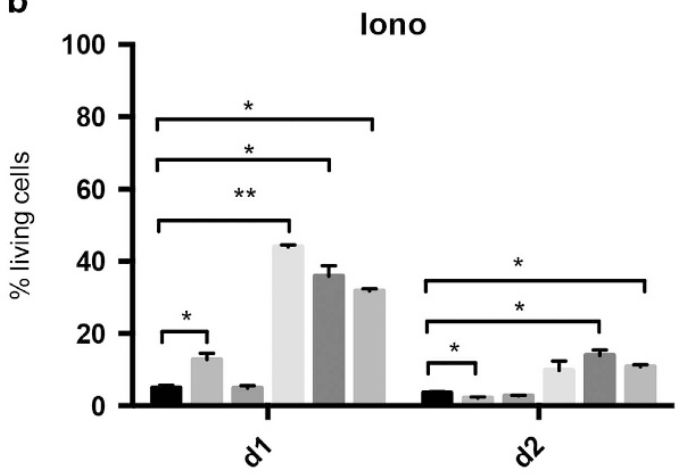

C

PMA

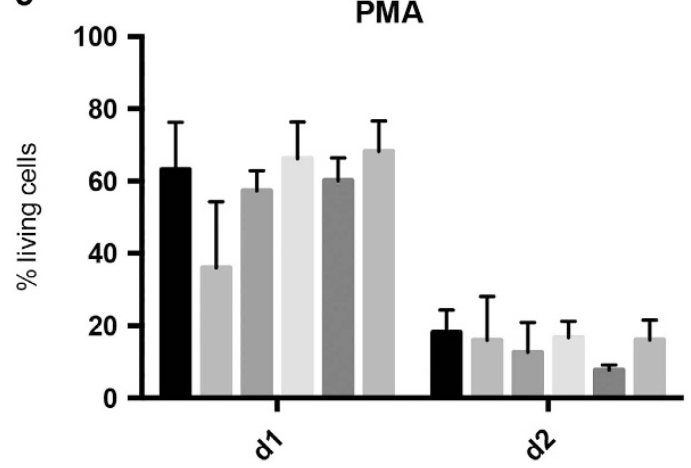


the loss of BIM protein 5 days after 4-OHT treatment, we observed residual BIM protein in the lymphoid cells from the $\mathrm{Bim}^{f / f I I} /$ Vav-CreER mice, whereas it was almost completely absent in the cells from the $B i m^{f / f I /} /$ Rosa-CreER animals at this time point (data not shown). This indicates that deletion of $\mathrm{Bim}^{f l}$ alleles occurs more rapidly and probably also more efficiently in the $\mathrm{Bim}^{f / f l} /$ Rosa-CreER strain than in the $\mathrm{Bim}^{\mathrm{fl} / \mathrm{fl} /}$ Vav-CreER strain, possibly because of the lower expression of CreER in the Vav-CreER strain.

However, the higher efficiency of Cre-mediated recombination of floxed target genes in the Rosa-CreER strain is accompanied by a higher toxicity observed in the animals upon treatment with 4-OHT. Accordingly, treatment of RosaCreER or Vav-CreER transgenic mice with 4-OHT for 5 consecutive days led to substantial destruction of lymphoid organs in the former, whereas these organs remained unaffected in the latter (Supplementary Figure 3 and data not shown). Both CreER strains are highly efficient at recombining the floxed Bim allele and, depending on the experimental requirements, are valuable tools for induced deletion of floxed alleles in mature or developing animals.

A significant leakage in CreER recombinase activity was observed in the $\mathrm{Bim}^{f / / f l} /$ Rosa26-CreER strain, as tail DNA obtained at weaning showed evidence of Cre-mediated deletion of the floxed Bim allele in $\sim 20 \%$ of these animals (data not shown). This was never observed in $\mathrm{Bim}^{\mathrm{fl} / \mathrm{fl}} / \mathrm{Vav}$-CreER-tg mice. Note that only mice with no evidence of $\mathrm{Bim}^{f l}$ recombination prior to tamoxifen administration were used in this study. Pertinently, we observed no abnormalities in splenic weights and thymocyte sub-population distribution in Bim $^{f / f l} / \mathrm{Nav}$-CreER-tg and Bim ${ }^{f / f t /} /$ Rosa-CreER-tg animals prior to 4-OHT treatment (data not shown). We therefore conclude that the occasional leakiness of CreER recombinase activity in the Rosa-CreER-tg mice must be limited to embryonic development and that despite this issue (which can be identified by tail DNA analysis), both this inducible CreER mouse strain and the Vav-CreER-tg strain are suitable tools for the inducible deletion of floxed genes.

\section{Materials and Methods}

Mice. Experiments with mice were conducted according to the guidelines of The Walter and Eliza Hall Institute Animal Ethics Committee. The generation of the conditional $\mathrm{Bim}^{f l}, \mathrm{MCl}-\mathrm{T}^{f l}$ and the RosaCreER mice, all on a C57BL/6 background, has been described previously. ${ }^{18,21,26}$ Vav-CreER transgenic mice were generated by replacing the hCD4 sequence of the Vav hematopoietic vector ${ }^{27}$ with the CreERT2 $2^{20}$ sequence using Sfi1/Not1 restriction sites. The Vav-CreER construct was linearized with Hindlll before pro-nuclear injection of the DNA into zygotes derived from C57BL/6 mice. Positive offspring were identified by PCR for the genomic integration of the Vav-CreER transgene.

To activate the latent CreER recombinase, mice were given $200 \mathrm{mg} / \mathrm{kg}$ tamoxifen (Sigma-Aldrich, Rowville, VIC, Australia) in peanut oil/ $10 \%$ ethanol each day for 5 days by oral gavage. ${ }^{28}$

Western blotting and WBC analysis. Cell extracts for western blot

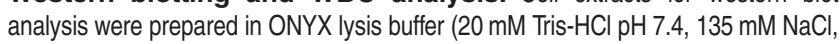
$1.5 \mathrm{mM} \mathrm{MgCl} 2,1 \mathrm{mM}$ EGTA, $1 \%$ Triton X-100, 10\% glycerol). Antibodies used include: rat anti-BIM (clones 3 C5 and CF7, ENZO Life Sciences, ${ }^{29}$ Waterloo, NSW, Australia), mouse anti- $\beta$-actin (Sigma AC-40, Rowville, VIC, Australia). Horseradish peroxidase-conjugated goat anti-mouse $\lg G$ or goat anti-rat $\lg G$ antibodies (both from Southern Biotech, Birmingham, AL, USA) served as secondary reagents and the enhanced chemoluminescence (ECL; GE Healthcare, Rydalmere, NSW, Australia) system was used for detection. WBC analysis was performed with an ADVIA blood analyzer (Siemens Healthcare Diagnostics, Tarrytown, NY, USA).

Intracellular immunofluorescent staining of BIM for flow cytometric analysis. Cells $\left(1 \times 10^{6}\right)$ from lymph nodes, spleen and thymus were isolated from mice of the indicated genotypes, fixed and permeabilized by suspension in $100 \mu$ of BD Cytofix/Cytoperm (BD Biosciences, San Jose, CA, USA) solution for $20 \mathrm{~min}$ on ice. Cells were then washed twice in Perm/Wash buffer (BD Biosciences) and stained with Alexa-647-conjugated BIM antibody (rat, clone \# $3 \mathrm{C} 5{ }^{29}$ ENZO Life Sciences). Analysis was performed in a FACSalibur (BD Biosciences).

Statistical analysis. Statistical comparisons were made using a two-tailed Student's t-test with Prism v.5.0 (GraphPad Software, Inc., La Jolla, CA, USA). $P$-values $<0.05$ were considered to indicate a statistically significant difference. $n$ indicates the number of mice analyzed for each genotype.

\section{Conflict of Interest}

The authors declare no conflict of interest.

Acknowledgements. We thank $M$ Robati for technical assistance, Dr LA O'Reilly for sharing reagents and expertise, G Siciliano and S O'Connor for mouse care, J Corbin for automated blood analysis, B Helbert and C Young for genotyping. This work was supported by the Australian NHMRC (Program Grant 461221, Independent Research Institutes Infrastructure Support Scheme Grant 361646, Research Fellowship 1042629 and Project Grant 1049720 (MJH)), the Leukemia and Lymphoma Society (Specialised Center of Research Grant 7015), and infrastructure support from the NHMRC (IRISS) and the Victorian State Government (OIS).

1. Czabotar PE, Lessene G, Strasser A, Adams JM. Control of apoptosis by the BCL-2 protein family: implications for physiology and therapy. Nat Rev Mol Cell Biol 2013; 15: 49-63.

2. Youle RJ, Strasser A. The BCL-2 protein family: opposing activities that mediate cell death Nat Rev Mol Cell Biol 2008; 9: 47-59.

3. Giam M, Huang DC, Bouillet $P$. BH3-only proteins and their roles in programmed cell death. Oncogene 2008; 27: S128-S136.

4. Merino D, Giam M, Hughes PD, Siggs OM, Heger K, O'Reilly LA et al. The role of BH3-only protein Bim extends beyond inhibiting Bcl-2-like prosurvival proteins. J Cell Biol 2009; 186: 355-362

5. Bouillet P, Metcalf D, Huang DCS, Tarlinton DM, Kay TWH, Köntgen F et al. Proapoptotic Bcl-2 relative Bim required for certain apoptotic responses, leukocyte homeostasis, and to preclude autoimmunity. Science 1999; 286: 1735-1738.

6. Bouillet P, Purton JF, Godfrey DI, Zhang L-C, Coultas L, Puthalakath $\mathrm{H}$ et al. BH3-only Bcl-2 family member Bim is required for apoptosis of autoreactive thymocytes. Nature 2002; 415 922-926.

7. Enders A, Bouillet $P$, Puthalakath $H, X u Y$, Tarlinton DM, Strasser A. Loss of the proapoptotic BH3-only Bcl-2 family member Bim inhibits BCR stimulation-induced apoptosis and deletion of autoreative B cells. J Exp Med 2003; 198: 1119-1126.

8. Pellegrini M, Belz G, Bouillet $P$, Strasser A. Shut down of an acute T cell immune response to viral infection is mediated by the pro-apoptotic Bcl-2 homology 3-only protein Bim. Proc Natl Acad Sci USA 2003; 100: 14175-14180.

9. Hughes PD, Belz GT, Fortner K, Budd RC, Strasser A, Bouillet P. Apoptosis regulators Fas and Bim cooperate in shutdown of chronic immune responses and prevention of autoimmunity. Immunity 2008; 28: 197-205.

10. Tagawa H, Karnan S, Suzuki R, Matsuo K, Zhang X, Ota A et al. Genome-wide array-based $\mathrm{CGH}$ for mantle cell lymphoma: identification of homozygous deletions of the proapoptotic gene BIM. Oncogene 2005; 24: 1348-1358.

11. Richter-Larrea JA, Robles EF, Fresquet V, Beltran E, Rullan AJ, Agirre X et al. Reversion of epigenetically mediated BIM silencing overcomes chemoresistance in Burkitt lymphoma. Blood 2010; 116: 2531-2542.

12. Zantl N, Weirich G, Zall H, Seiffert BM, Fischer SF, Kirschnek S et al. Frequent loss of expression of the pro-apoptotic protein Bim in renal cell carcinoma: evidence for contribution to apoptosis resistance. Oncogene 2007; 26: 7038-7048.

13. Puthalakath $H$, O'Reilly LA, Gunn P, Lee L, Kelly PN, Huntington ND et al. ER stress triggers apoptosis by activating BH3-only protein Bim. Cell 2007; 129: 1337-1349.

14. Schwenk F, Kuhn R, Angrand PO, Rajewsky K, Stewart AF. Temporally and spatially regulated somatic mutagenesis in mice. Nucleic Acids Res 1998; 26: 1427-1432.

15. Feil R, Brocard J, Mascrez B, LeMeur M, Metzger D, Chambon P. Ligand-activated sitespecific recombination in mice. Proc Natl Acad Sci USA 1996; 93: 10887-10890. 
16. Ogilvy S, Elefanty AG, Visvader J, Bath ML, Harris AW, Adams JM. Transcriptional regulation of vav, a gene expressed throughout the hematopoietic compartment. Blood 1998; 91 : 419-430.

17. Bouillet $P$, Zhang LC, Huang DC, Webb GC, Bottema CD, Shore $P$ et al. Gene structure alternative splicing, and chromosomal localization of pro-apoptotic Bcl-2 relative Bim. Mamm Genome. 2001; 12: 163-168.

18. Raynor J, Sholl A, Plas DR, Bouillet P, Chougnet CA, Hildeman DA. IL-15 fosters age-driven regulatory T cell accrual in the face of declining IL-2 levels. Front Immunol 2013; 4: 161.

19. Schwenk F, Baron U, Rajewsky K. A cre-transgenic mouse strain for the ubiquitous deletion of loxP-flanked gene segments including deletion in germ cells. Nucleic Acids Res 1995; 23 5080-5081.

20. Indra AK, Warot X, Brocard J, Bornert JM, Xiao JH, Chambon P et al. Temporally-controlled site-specific mutagenesis in the basal layer of the epidermis: comparison of the recombinase activity of the tamoxifen-inducible Cre-ER(T) and Cre-ER(T2) recombinases. Nucleic Acids Res 1999; 27: 4324-4327.

21. Glaser $S$, Lee EF, Trounson E, Bouillet $P$, Wei A, Fairlie WD et al. Anti-apoptotic Mcl-1 is essential for the development and sustained growth of acute myeloid leukemia. Gene Dev 2012; 26: 120-125.

22. Kelly GL, Grabow S, Glaser SP, Fitzsimmons L, Aubrey BJ, Okamoto T et al. Targeting of MCL-1 kills MYC-driven mouse and human lymphomas even when they bear mutations in p53. Gene Dev 2014; 28: 58-70.

23. Soriano P. Generalized lacZ expression with the ROSA26 Cre reporter strain. Nat Genet 1999; 21: 70-71.

24. Villunger A, Michalak EM, Coultas L, Mullauer F, Bock G, Ausserlechner MJ et al. p53- and drug-induced apoptotic responses mediated by $\mathrm{BH} 3-$ only proteins puma and noxa. Science 2003; 302: 1036-1038.
25. Pierson W, Cauwe B, Policheni A, Schlenner SM, Franckaert D, Berges J et al. Antiapoptotic Mcl-1 is critical for the survival and niche-filling capacity of Foxp3(+) regulatory T cells. Nat Immunol 2013; 14: 959-965.

26. Seibler J, Zevnik B, Kuter-Luks B, Andreas S, Kern H, Hennek T et al. Rapid generation of inducible mouse mutants. Nucleic Acids Res 2003; 31: e12.

27. Ogilvy S, Metcalf D, Gibson L, Bath ML, Harris AW, Adams JM. Promoter elements of vav drive transgene expression in vivo throughout the hematopoietic compartment. Blood 1999; 94: 1855-1863.

28. Anastassiadis K, Glaser S, Kranz A, Berhardt K, Stewart AF. A practical summary of sitespecific recombination, conditional mutagenesis, and tamoxifen induction of CreERT2. Methods Enzymol 2010; 477: 109-123.

29. O'Reilly LA, Kruse EA, Puthalakath H, Kelly PN, Kaufmann T, Huang DC et al. MEK/ERKmediated phosphorylation of Bim is required to ensure survival of $T$ and $B$ lymphocytes during mitogenic stimulation. J Immunol 2009; 183: 261-269.

Cell Death and Disease is an open-access journal published by Nature Publishing Group. This work is licensed under a Creative Commons Attribution 4.0 International Licence. The images or other third party material in this article are included in the article's Creative Commons licence, unless indicated otherwise in the credit line; if the material is not included under the Creative Commons licence, users will need to obtain permission from the licence holder to reproduce the material. To view a copy of this licence, visit http://creativecommons.org/licenses/by/4.0

Supplementary Information accompanies this paper on Cell Death and Disease website (http://www.nature.com/cddis) 